\title{
Lojistik Performans Değerlendirmesi İçin Bulanık AHP ve Gri İlişkisel Analiz Yöntemleri İle Bütünleşik Bir Yaklaşım
}

\author{
Integrated Approach Of Fuzzy AHP and Grey Relational Analysis For Logistic Performance Evaluation \\ Gökçe CANDAN ${ }^{\text {a* }}$ \\ *Dr. Öğr. Üyesi, Sakarya Üniversitesi, Siyasal Bilgiler Fakültesi, Ekonometri Bölümü, 54187 Serdivan / SAKARYA \\ ORCID:0000-0002-5966-0009
}

\section{MAKALE BİLGİSI}

\section{Makale Geçmişi:}

Başvuru tarihi: 02 Ocak 2019

Düzeltme tarihi: 05 Mayıs 2019

Kabul tarihi: 17 Mayıs 2019

\section{Anahtar Kelimeler:}

Lojistik Performans

Bulanık AHP

Gri İlişkisel Analiz

\section{ARTICLE INFO}

\section{Article history:}

Received 02 January 2019

Received in revised form 05 May 2019

Accepted 17 May 2019

\section{Keywords:}

Logistics Performance

Fuzzy AHP

Grey Relational Analysis

\section{ÖZ}

Son yıllarda hızlıca gelişme gösteren lojistik hizmet anlayışı, lojistik servis sağlayıcılarını gittikçe daha fazla müşteri odaklı hizmet üretmeye itmektedir. Lojistik sektöründe rekabet edebilmek için bilgi teknolojileriyle entegre sistemler kullanmak etkinlik ve verimliliği artırırken müşteri memnuniyetini de geliștirmektedir. Sahip olunan bilișim ve ulaştırma altyapılarını, kalifiye insan kaynağı ile etkin bir şekilde değerlendiren servis sağlayıcılarının lojistik performanslarının da oldukça yüksek olduğu görülmektedir. Bu çalışmada OECD üyesi 10 ülke için lojistik performans değerlendirmesi yapılmıştır. Bunun için ele alınan değerlendirme kriterlerine ait ağırlıklar, çok kriterli karar verme tekniklerinden bulanık AHP metodu ile hesaplanmış daha sonra ülkelerin lojistik performansına göre sıralama gri ilişkisel analiz metoduyla gerçekleştirilmiştir. Ülkelerin lojistik performanslarının öncelikle ithalat ve ihracat teslim sürelerine daha sonra ise kullandıkları altyapıların kalitesine bağlı olduğu sonucuna erişilmiştir.

\section{Giriş}

Günümüzde İnsan kaynağ kaynakların bir sistem çerçevesinde bir araya getirilerek müşteri talep ve beklentilerini üretim faaliyetleriyle dengeli bir şekilde yürütebilmek tedarik zinciri yönetimi olarak tanımlanabilir. Tedarik zincirinin önemli bir parçası olan lojistik hizmetler, etkin ve verimli bir şekilde sağlandığında tedarik zincirinin performansını da artırmaktadır. Günümüzde teknoloji ve ticaret anlayışı hızla gelişmekte olduğundan lojistik hizmet anlayışlarının da farklılaştığı bilinmektedir. Müşteri talepleriyle doğrudan etkilenen lojistik faaliyetlerin performansı tedarik zincirinin takip ve izlenebilirliği ile artmaktadır. Lojistik faaliyetlerin izleme ve takibi için güçlü bir bilişim ve ulaştırma altyapısı gereklidir. Bilişim sistemleriyle; lojistik faaliyetler gerçekleşirken sevk edilen ürünlerin güncel, geçmiş ve gelecek lokasyonları izlenebilmekte, bu izleme ve takip sistemleri ise müşteri memnuniyetine olumlu yansımaktadır. Lojistik hizmet üreten işletmelerin farklı tiplerde bilgi teknolojilerini kullandığı görülmektedir. Bunlardan bazıları uluslararası karayolu eşya taşımacılığı

\footnotetext{
* Sorumlu Yazar / Corresponding Author

e-posta: gcandan@sakarya.edu.tr
} 
bilgi sistemi, filo yönetimi ve araç takip sistemleri, sürücü bilgi takip sistemi gibi sistemlerdir. Kullanılan bu teknolojilerin ortak amac1 ise lojistik hizmetlerin verimliliğini ve performansını artırmak, maliyetleri azaltmak bunları gerçekleştirirken de müşteri ilişkileri ve memnuniyetini geliştirmektir.

Literatür araştırması yapıldığında, ele alınan çalışmalardaki "lojistik performans" tanımı farklı farklı ve sektörlere göre de değişiklik göstermektedir. Bu sebeple çalışmalarda ele alınan değerlendirme kriterleri de birbirlerinden farklı olmakta ve yine sektörlere göre değişiklik arz etmektedir. $\mathrm{Bu}$ çalışmalarda ele alınan değerlendirme kriterlerinde ortak bir husus olarak, mutlaka zamanında teslimat, güvenilirlik veya müşteri memnuniyeti ifadelerinden birinin yer almış olması dikkat çekicidir (Korpela ve Tuominen (1996), Anderson vd., (1989), Wang vd., (2015), Fawcett ve Cooper (1998), Ramanathan (2010) Lai vd., (2008), Fugate vd., (2012) , Liu ve Lyons (2011) , Piriyakul (2011) , Hsiao vd., (2010) Hanaoka ve Kunadhamraks (2009)).

Dünya Bankası ülkeleri lojistik açıdan verimlilik, kalite ve yeterlilik ölçümlerine tabi tutmakta ve 2007 y1lından bu yana periyodik olarak bir lojistik performans indeksi (LPI) raporu yayınlamaktadır. $\mathrm{Bu}$ rapor ile ülkelerin sahip oldukları gümrükleri ve altyapıları verimli kullanıp kullanmadıkları, uluslararası sevkiyat sistemlerinin kalite, maliyet, güvenilirlik ve zamanlama konusundaki performansları ölçülmektedir. Dünya bankası bu ölçümleri gerçekleştirmek için ülkelerdeki önemli ihracat ve ithalat ortağı firmalara internet üzerinden puanlama (1-5 arasında) sistemine dayalı bir anket uygulamaktadır. Dünya Bankası LPI'da ülkeler aldıkları puana göre lojistik dostu, istikrarlı performansta, k1smen performans gösteren ve lojistik dostu olmayan ülkeler şeklinde kategorize edilmektedir. Türkiye LPI siralamasinda 2014'te 30. ülke, 2016'da 34. olup lojistik dostu ülkeler kategorisinde yer almışken 2018'de ise 47. Sıraya gerilemiştir. (T.C. Gümrük Ve Ticaret Bakanlığg1,2017; Dünya Bankası, 2018)

Lojistik performans değerlendirmesi ile ilgili çalışmalara 90'lı yıllardan itibaren rastlanmaktadır. Caplice ve Sheffi (1995) lojistik performans ölçüm sistemlerini iki farklı sektörde örnek olay üzerinden değerlendirmişler ve sektörler birbirinden çok farklı olsa da lojistik stratejilerinin benzer olduğu sonucuna erişmişlerdir. Günümüzde hala lojistik performans değerlendirmesi konusunda kesin ve net tek bir sistem olmamakla birlikte literatürde, yenilenen teknikler ile geliştirilen değerlendirme sistemleriyle karşılaşılmaktadır. Bunlardan birçoğu çok kriterli karar verme teknikleriyle geliştirilmiştir ve bir kısmı şöyledir:

Chan vd. (2006) çalışmalarında posta hizmetleri sektöründe lojistik performans ölçümü için AHP metodunu kullanmışlardır. Kazancoğlu vd. (2018), yeşil tedarik zinciri performansını çimento sektöründe Bulanık Dematel Metodu ile değerlendirmişlerdir. Performans kriterleri olarak çevresel, ekonomik, lojistik, operasyonel, organizasyonel ve pazarlama performansı unsurlarını ele almışlardır. Hanaoka ve Kunadhamraks (2009), çalışmalarında intermodal yük lojistiğine etki eden faktörleri bulanık AHP ile değerlendirmişlerdir. Ele aldıkları faktörlerin ağırlıkları büyükten küçüğe lojistik maliyetler, hizmet kalitesi, güvenilirlik ve güvenlik şeklinde olmuştur. Ramana vd. (2013), yalın çevik tedarik zinciri performansına etki eden faktörleri açıklayıcı faktör analizi ve bulanık AHP metotlarıyla değerlendirmişlerdir. Buna göre faktörlerin önem dereceleri büyükten küçüğe müşteri hizmet performansı, esneklik, operasyonel performans ve organizasyonel performans olarak sıralanmıştır. Özceylan vd. (2016); çalışmalarında coğrafi bilgi sistemini de kullanarak elde ettikleri verilerle, Türkiye'deki 81 ilde lojistik performans değerlendirmesi yapmışlardır. Kriter ağırlıklarını AHP ve ANP metotlarıyla, kriter sıralamalarını ise AHP, ANP ve TOPSIS metotlarıyla ele aldıkları beş farklı yaklaşım önermişlerdir. Türkiye'de lojistik performans öncüsü olarak ise İstanbul, İzmir ve Hatay şehirleri olduğu belirlenmiştir. Jothimani ve Sarmah (2014), SCOR, Bulanık AHP ve TOPSIS metotlarıyla bütünleşik bir yaklaşım önererek üçüncü parti lojistik tedarik zinciri performansını ölçmüşlerdir.

Performans değerlendirmesi için birçok çalışmada ise farklı sayısal yöntemler kullanıldığı görülmekte bazı çalışmalarda ise literatür araması şeklinde genel değerlendirme araştırmaları yapıldığı belirlenmiştir. Bunlardan bazıları şu şekildedir:

Rafele ve Cagliano (2006) çalışmalarında otomotiv sektöründe lojistik performansını, performans ölçülerini finansal olan ve olmayan şeklinde ikiye ayırarak dinamik sistem yaklaşımı ile analiz etmişlerdir. Puertas vd. (2014) Avrupa'da 2005 ve 2010 yıllarındaki lojistik performans ve ihracat rekabeti arasındaki ilişkiyi matematiksel bir metotla kıyaslayarak değerlendirmişler ve Avrupa Birliği'nin lojistik performans üzerine olumlu katkılarda bulunduğunu, üye ülkelerin ihracat miktarı arttıkça lojistik performanslarının da arttığı sonucuna ulaşmışlardır. Erkan (2014), regresyon analiziyle 113 ülkeye ait verilerle elde ettiği sonuçlara göre ülkelerin lojistik performanslarının en önemli etkenlerinin demiryolu altyapısı ve liman altyapısının kalitesi olduğunu belirlemiştir. Çalışmada lojistik performansını isteyen bir ülkenin öncelikle demiryolu ve liman altyapısının kalitesini iyileştirmesi gerektiği belirtilmiştir. Avelar-Sosa vd. (2015); tedarik zinciri performansına geleneksel ve uluslararası lojistik politikaların etkilerini yapısal eşitlik modellemesiyle araştırmışlardır. Neticede geleneksel lojistik politikalarının envanter üzerinde direkt bir etkisi olduğunu, bu etkinin müşteri memnuniyetini artırdığını ve ekonomik açıdan olumlu etkiler yarattığını ortaya koymuşlardır. Bayraktutan ve Özbilgin (2015), lojistik performans ölçütleriyle ilgili gerçekleştirdikleri literatür araştırması neticesinde lojistik performans ölçülerini faktör koşulları, iktisadi koşullar ve dış çevre koşulları olmak üzere üç temel gruba ayırmışlardır. Ahi ve Searcy (2015) yeşil tedarik zinciri yönetimi ve sürdürülebilir tedarik zinciri yönetimi ile ilgili literatürde yayınlanan 2555 farklı performans ölçütünü analiz etmişlerdir. En çok kullanılan ölçütlerin başında kalite, hava emisyonları ve enerji tüketimi gelmektedir. Lin ve Cheng (2018) doğrusal regresyon ile ele aldıkları ülkelerdeki lojistik performans indeksleri ve gayri safi yurt içi hasılaları arasındaki ilişkiyi değerlendirmişlerdir. Ayrıca ülkelere komşu olan ülkelerin durumunu da değerlendirmişler ve ülkelerin lojistik performans indekslerinin GSYH dan ziyade komşularının lojistik performanslarına bağlı olduğu sonucuna varmışlardır. 
$\mathrm{Bu}$ çalışmada lojistik performans ölçüm ve değerlendirmesi için bütünleşik bulanık analitik hiyerarşi Prosesi (AHP) ve Gri İlişkisel Analiz (GİA) yöntemleriyle yeni bir metot önerilmektedir. Literatürde; bütünleşik bir şekilde, bulanık AHP ve GİA yöntemlerini kullanarak lojistik performans değerlendirmesi gerçekleştiren bir çalışmaya rastlanmamıştır. Bundan dolayı bu çalışma lojistik performans değerlendirmesi için yeni bir yaklaşım içermektedir. Çalışmada ele alınan örnek vakada ise OECD üyesi 10 ülkenin lojistik performansları gerçek veriler ile değerlendirilmiştir. Çalışma bu yönüyle de yenilikçi bir yaklaşım sunmaktadır.

$\mathrm{Bu}$ çalışma uluslararası nitelikte bir performans değerlendirme örneği sunmuş olsa da; farklı sektörlerde lojistik performans değerlendirmesi için farklı farklı kriterler ile kullanılabilir esnek bir metot içermektedir.

İlerleyen bölümlerde; bulanık AHP ve GİA yöntemleri detaylıca ele alınmış ardından bu yöntemler kullanılarak gerçekleştirilen lojistik performans değerlendirmesi için örnek bir vaka sunulmuştur.

\section{Bulanik AHP Metodu}

Analitik hiyerarşi Prosesi (AHP) nicel veya nitel kriterler üzerinden karar veren, birden fazla karar vericinin değerlendirme yaparak birden çok alternatifi değerlendirebildiği bir, çok kriterli karar verme (ÇKKV) yöntemidir. $\mathrm{Bu}$ yöntemde öncelikle karar verici uzman kişilerin amaçları ortaya konulur. Bu amaçlara yönelik ana ve alt kriterlerden ve her bir kriter için alternatiflerden oluşan bir hiyerarşik yapı ortaya çıkartılır. Daha sonra kriterler birbiriyle kıyaslanarak ikili karşılaştırma matrisleri elde edilir. İkili karşılaştırmadan kasıt kriterlerin birbirlerine göreli üstünlüklerinin ortaya konulmasıdır. Ardından öncelikler hesaplanır ve matrislerin tutarlı olup olmadığı bir tutarlılık oranı olan 0,1 ile kıyaslanır. Eğer tutarlılık oranı 0,1 'den küçük ise elde edilen karşılaştırma matrisi tutarlıdır. Ve son olarak göreli önem değerlerine göre alternatifler sıralanır en yüksek değere sahip olan alternatif üzerinde karar alınır. AHP bu haliyle ikili karşılaştırma matrisleri oluşturulurken uzmanların kesin veya net ifade edemediği kararsız kaldığı durumları modelleyememektedir. Bu ihtiyaçtan yola çıkarak Bulanık AHP metodu geliştirilmiş ve kriterlerin birbirlerine göre üstünlükleri bir değerler aralığı şeklinde ifade edilerek ele alınmıştır. Literatürde bulanık küme teorisindeki üçgen veya yamuk üyelik fonksiyonlarıyla ifade edilen farklı Bulanık AHP uygulamaları mevcuttur. (Buckley 1985, Chang 1996, Laarhoven ve Pedrycz 1983)). Bu çalışmada Chang (1996) tarafindan genişletme analizi yöntemini öneren bulanık AHP metodu kullanılmıştır. $\mathrm{Bu}$ yöntemde kullanılan dilsel değişkenler ve bunlara karşılık gelen üçgensel bulanık sayılar Tablo 1'de görülmektedir.
Tablo 1. Dilsel Değişkenler ve Üçgensel Bulanık Sayılar

\begin{tabular}{llc}
\hline Dilsel Değişkenler & $\begin{array}{l}\text { Bulanık } \\
\text { Ölçek }\end{array}$ & Karşılık Ölçek \\
\hline $\begin{array}{l}\text { Eşit Derecede Önemli } \\
\text { Orta Derecede Önemli }\end{array}$ & $\begin{array}{l}(1,1,1) \\
(1,3,5)\end{array}$ & $(1,1,1)$ \\
$\begin{array}{l}\text { Kuvvetli Derecede } \\
\text { Önemli }\end{array}$ & $(3,5,7)$ & $(1 / 7,1 / 3,1)$ \\
$\begin{array}{l}\text { Çok Kuvvetli Derecede } \\
\text { Önemli }\end{array}$ & $(5,7,9)$ & $(1 / 9,1 / 7,1 / 5)$ \\
Mutlak Derecede Önemli & $(7,9,9)$ & $(1 / 9,1 / 9,1 / 7)$ \\
\hline
\end{tabular}

Yöntemin aşamaları şu şekildedir:

$X=\left\{x_{1}, x_{2}, \ldots, x_{n}\right\}$ nesneler kümesi, $G=\left\{g_{1}, g_{2}, \ldots, g_{m}\right\}$ amaçlar kümesi olsun.

$M_{g_{i}}^{1}, M_{g_{i}}^{2}, \ldots, M_{g_{i}}^{m}, \quad i=1,2, \ldots, n$ şeklinde her bir nesne için $\mathrm{m}$ adet genişletme analizi değeri elde edilir.

Genişletmeyle anlatılmak istenen, nesnenin amacı ne kadar gerçekleştirdiğini ifade etmektir.

$M_{g_{i}}^{j}(j=1,2, \ldots, m)$ değerlerinin tümü üçgensel bulanık sayılardir.

Adım 1: i.nesne için bulanık büyüklük değeri hesaplanir.

Öncelikle bulanık genişletme değeri;

$$
S_{i}=\sum_{j}^{m} M_{g_{i}}^{j} \otimes\left[\sum_{i=1}^{n} \sum_{j=1}^{m} M_{g_{i}}^{j}\right]^{-1}
$$

eşitliğiyle hesaplanır. $\mathrm{m}$ adet genişletme analizinin bulanık toplama işlemi

$$
\sum_{j}^{m} M_{g_{i}}^{j}=\left(\sum_{j=1}^{m} l_{j}, \sum_{j=1}^{m} m_{j}, \sum_{j=1}^{m} u_{j}\right)
$$

şeklinde uygulanır ve;

$$
\begin{aligned}
\sum_{i=1}^{n} \sum_{j=1}^{m} M_{g_{i}}^{j} & =\left(\sum_{i=1}^{n} l_{i}, \sum_{i=1}^{n} m_{i}, \sum_{i=1}^{n} u_{i}\right)(3) \\
{\left[\sum_{i=1}^{n} \sum_{j=1}^{m} M_{g_{i}}^{j}\right]^{-1} } & =\left(\frac{1}{\sum_{i=1}^{n} u_{i}}, \frac{1}{\sum_{i=1}^{n} m_{i}}, \frac{1}{\sum_{i=1}^{n} l_{i}}\right)(4)
\end{aligned}
$$

şeklinde tersi elde edilir.

Adım 2: Elde edilen bulanık sayılar karşılaştırılarak ağırlık değerleri elde edilir.

$\mathrm{M}_{2}=\left(\mathrm{l}_{2}, \mathrm{~m}_{2}, \mathrm{u}_{2}\right) \geq \mathrm{M}_{1}=\left(\mathrm{l}_{1}, \mathrm{~m}_{1}, \mathrm{u}_{1}\right)$ üçgensel bulanık sayılarının karşıllaştırılması için;

$$
\begin{gathered}
\mathrm{V}\left(\mathrm{M}_{2} \geq \mathrm{M}_{1}\right)=\sup \left[\min \left(\mu_{\mathrm{M}_{1}}(\mathrm{x}), \mu_{\mathrm{M}_{2}}(\mathrm{y})\right)\right] \\
\mathrm{V}\left(\mathrm{M}_{2} \geq \mathrm{M}_{1}\right)=\operatorname{hgt}\left(\mathrm{M}_{1} \cap \mathrm{M}_{2}\right)=\mu_{\mathrm{M}_{2}}(\mathrm{~d})
\end{gathered}
$$


$=\left\{\begin{array}{cc}1, & \text { eğer } m_{2} \geq m_{1}, \\ 0, & \text { eğer } l_{1} \geq u_{2}, \\ \frac{l_{1}-u_{2}}{\left(m_{2}-u_{2}\right)-\left(m_{1}-l_{1}\right)}, & \text { diğer durumlarda, }\end{array}\right.$

Eşitliğinden yararlanılır. Burada $\mathrm{d} \mu_{\mathrm{M}_{1}}$ ve $\mu_{\mathrm{M}_{2}}$ arasındaki en yüksek kesişim noktası olan d'nin düşey eksenidir. $\mathrm{M}_{1}$ ve $\mathrm{M}_{2}$ nin kıyaslanabilmesi için hem $\mathrm{V}\left(\mathrm{M}_{1} \geq \mathrm{M}_{2}\right)$ hem de $\mathrm{V}\left(\mathrm{M}_{2} \geq \mathrm{M}_{1}\right)$ nin hesaplanmasına ihtiyaç vardır.

Adım 3: Konveks bir bulanık sayının k adet bulanık sayıdan,

$M_{i}=(i=1,2, \ldots, k)$, daha büyük olabilirlik derecesi şu şekilde tanımlanır:

$\mathrm{V}\left(\mathrm{M} \geq \mathrm{M}_{1}, \mathrm{M}_{2}, \ldots, \mathrm{M}_{\mathrm{k}}\right)=$

$V\left[\left(M \geq M_{1}\right)\right.$ and $\left(M \geq M_{2}\right) \ldots$ ve $\left.\left(M \geq M_{k}\right)\right]$

$$
=\min V\left(M \geq M_{i}\right)
$$

$$
i=1,2, \ldots, k
$$

$\mathrm{d}^{\prime}\left(\mathrm{A}_{\mathrm{i}}\right)=\operatorname{minV}\left(\mathrm{S}_{\mathrm{i}} \geq \mathrm{S}_{\mathrm{k}}\right) \mathrm{k}=1,2, \ldots, \mathrm{n}$;

$$
\mathrm{k} \neq \mathrm{i}
$$

Ağırlık vektörü

$W^{\prime}=\left(d^{\prime}\left(A_{1}\right), d^{\prime}\left(A_{2}\right), \ldots, d^{\prime}\left(A_{n}\right)\right)^{T}$ şeklinde elde edilir.

Burada $A_{i}(i=1,2, \ldots, n) n$ adet elemandir.

Adım 4 : Normalize edilmiş ağırlık vektörü hesaplanır.

$W=\left(d\left(A_{1}\right), d\left(A_{2}\right), \ldots, d\left(A_{n}\right)\right)^{T}, W$ bulanı olmayan değerdir(9)

$$
d\left(A_{i}\right)=\frac{d^{\prime}\left(A_{i}\right)}{\sum_{i=1}^{n} A_{i}}
$$

biçiminde hesaplanır.

\section{Gri İlişkisel Analiz Yöntemi (GİA)}

Belirsizliğin sayısal forma dönüştürülmesi için Ju Long Deng (1982) tarafından Gri Sistem Teorisi (GST) adlı bir yöntem önerilmiştir. GST stokastik veya bulanık mantık sistemleriyle çözülemeyen problemleri tahminlemeyi amaçlamaktadır. Burada gri kavramı siyah ve beyaz sistemlerin haricinde bir sistemi tanımlamakta ve bu sistemde parametreler, sistem davranışı veya sistem yapısı hakkında eksik bilgiler mevcuttur. GİA yöntemi ise GST temelli bir karar verme tekniğidir.

GİA yöntemi gri bir sistemdeki her bir faktörün referans değer ile arasındaki niceliksel veya niteliksel ilişkiyi kıyaslamaktadır. GİA yönteminin aşamaları; veri setinin hazırlanması ve karar matrislerinin oluşturulması, referans ve karşılaştırma serilerinin oluşturulması, karar matrisinin normalizasyonu, mutlak değer tablosunun elde edilmesi, gri ilişki katsayılarının hesaplanması ve gri ilişki derecelerinin belirlenmesi olmak üzere 6 aşamadan oluşmaktadır ( $\mathrm{Wu}$, 2002). İşlem adımları daha kapsamlı bir şekilde anlatılacak olursa;
Adım 1: Veri setinin hazırlanması ve karar matrislerinin oluşturulması

Ele alınan karar probleminde karşılaştırılacak m adet faktör serisi belirlenir.

xi'ler alternatifleri göstermekte ve xi(j) ler ise her bir alternatifin her bir kriter için aldığ 1 değeri göstermektedir.

$$
\begin{aligned}
& x_{i}=\left(x_{i}(j), \ldots . ., x_{i}(n)\right), i=1,2, \ldots . m j \\
& =1,2, \ldots . n
\end{aligned}
$$

Karar matrisi ise eşitlik 12'deki gibi oluşturulur.

$\mathrm{X}$

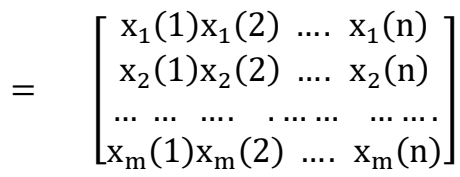

Adım 2: Referans Serisinin ve Karşılaştırma Matrisinin Oluşturulması

Referans serisi şu şekilde formüle edilir.

$$
\mathrm{x}_{0}=\left(\mathrm{x}_{0}(\mathrm{j})\right) \quad \text { ve } \mathrm{j}=
$$

$1,2, \ldots . \mathrm{n}$

Burada $\mathrm{x}_{0}(\mathrm{j}) \quad \mathrm{j}$. kriterin en uygun değerini göstermektedir. Referans serisindeki değerler, karar matrisindeki her bir kriterin en iyi değerini alır.

Adım 3: Karar Matrisinin Normalize Edilmesi ve Normalizasyon Matrisinin Oluşturulması

Farklı özellikteki serilerin karşılaştırılabilmesi için veriler standart bir hale dönüştürülür bu işleme normalizasyon denilmektedir. Ele alınan problemin amaç fonksiyonunun fayda, maliyet veya optimum olma özelliğine göre normalizasyon işlemi farklılaşmaktadır.

Fayda durumunda; serideki değerlerin en büyüklenmesi hedeflenecek ve bu durumda normalizasyon eşitlik 14 ile gerçekleşecektir:

$$
x_{i}^{*}=\frac{x_{i}(j)-{ }_{j}^{\min _{j}} x_{i}(j)}{\max _{j} x_{i}(j)-\min _{j} x_{i}(j)}
$$

Maliyet durumunda; serideki değerlerin en küçüklenmesi hedeflenecek ve bu durumda normalizasyon eşitlik 15 ile gerçekleşecektir:

$$
x_{i}^{*}=\frac{\max _{j} x_{i}(j)-x_{i}(j)}{\max _{j} x_{i}(j)-\min _{j} x_{i}(j)}
$$

Optimum durumda; serideki değerlerin belirlenen optimal bir değere göre normalizasyonu yapılacaktır ve bu durumda normalizasyon eşitlik 16 ile gerçekleşecektir:

$$
x_{i}^{*}=\frac{\left|x_{i}(j)-x_{o b}(j)\right|}{\max _{j} x_{i}(j)-x_{o b}(j)}
$$

Uygun normalizasyon işlemi ardından karar matrisi aşağıdaki gibi normalizasyon matrisine dönüştürülmüş olur. 


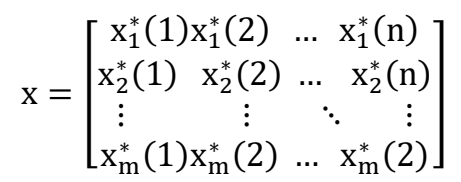

Adım 4: Mutlak Değer Tablosunun Oluşturulması:

Eşitlik 18 ile $\mathrm{x}_{0}^{*}$ ile $\mathrm{x}_{\mathrm{i}}^{*}$ arasındaki farkın mutlak değeri $\Delta_{0 \mathrm{i}}(j)$ elde edilir.

$$
\begin{aligned}
& \Delta_{0 \mathrm{i}}=\left|\mathrm{x}_{0}^{*}(\mathrm{j})-\mathrm{x}_{\mathrm{i}}^{*}(\mathrm{j})\right| \quad \mathrm{i}=1,2, \ldots . \mathrm{m} \\
& \mathrm{j}= 1,2, \ldots . \mathrm{n} \\
& \mathrm{x}_{\mathrm{i}}^{*}=\left[\begin{array}{cccc}
\Delta_{01}(1) \Delta_{01}(2) & \cdots & \Delta_{01}(\mathrm{n}) \\
\Delta_{02}(1) \Delta_{02}(2) & \cdots & \Delta_{02}(\mathrm{n}) \\
\vdots & \vdots & \vdots & \vdots \\
\Delta_{0 \mathrm{~m}}(1) \Delta_{0 \mathrm{~m}}(2) & \cdots & \Delta_{0 \mathrm{~m}}(\mathrm{n})
\end{array}\right]
\end{aligned}
$$

\section{Adım 5: Gri İlişkisel Katsayı Matrisinin Oluşturulması}

Eşitlik 20 ile gri ilişkisel katsayı matrisi elde edilir.

$$
\begin{aligned}
\Delta_{\text {max }} & =\max _{\mathrm{i}} \max _{\mathrm{j}} \Delta_{0 \mathrm{i}}(\mathrm{j}) \quad \text { ve } \\
\Delta_{\text {min }} & =\min _{\mathrm{i}} \min _{\mathrm{j}} \Delta_{0 \mathrm{i}}(\mathrm{j}) \text { olmak üzere; } \\
\gamma_{0 \mathrm{i}}(\mathrm{j}) & =\frac{\Delta_{\min }+\zeta \Delta_{\max }}{\Delta_{0 \mathrm{i}}(\mathrm{j})+\zeta \Delta_{\max }}
\end{aligned}
$$

Burada yer alan $\zeta$ değeri ayırıcı katsayıdır ve $[0,1]$ arasında değerler alır. Literatürde genellikle $\zeta=0,5$ olarak kullanılmaktadır.

\section{Adım 6: Gri İlişki Derecelerinin Belirlenmesi}

$\mathrm{Bu}$ aşamada $\mathrm{x}_{\mathrm{i}}^{*}$ ve $\mathrm{x}_{0}^{*}$ serileri arasında karşılaştırma yapılarak referans seri $\mathrm{x}_{0}^{*}$ a olan benzerlik araştırılır. Benzerliğin büyüklüğü ile gri ilişkisel derecenin büyüklüğü doğru orantılı olmaktadır. Gri ilişkisel dereceler hesaplanırken;

$$
\Gamma_{0 i}=\frac{1}{n} \sum_{j=1}^{n} \gamma_{0 i}(j) \quad i=1,2, \ldots, m
$$

Kriterlerin önem dereceleri eşit olduğu durumda Eşitlik 21 kullanılır.

$$
\Gamma_{0 i}=\frac{1}{n} \sum_{j=1}^{n} w_{i}(j) \gamma_{0 i}(j) \quad i=1,2, \ldots, m
$$

Kriterlerin önem dereceleri farklı olduğu durumda Eşitlik 22 kullanilır.

Burada $\Gamma_{0 \mathrm{i}}$ gri ilişkisel derece, $\mathrm{w}_{\mathrm{i}}$ ise kriter ağırlı̆̆ıdır (önem derecesi).

Gri ilişsi dereceleri hesaplandıktan sonra büyükten küçüğg doğru sıralama yapılır en büyük ilişki derecesine sahip olan alternatif üzerinde karar verilir.

\section{Lojistik Performans Değerlendirmesi}

Çalışmanın bu bölümünde bulanık AHP ve Gri İlişkisel Analiz yöntemleriyle 10 adet OECD üyesi ülkenin lojistik performansları değerlendirilmiştir.

\subsection{Uygulama Aşamaları}

Şekil 1'de lojistik performans değerlendirmesi uygulamasının aşamaları görülmektedir. Dünya Bankası veri tabanından ülkelerin lojistik performansına ait kriterler ve yapılan anketler karşıllı̆ı̆ında elde edilmiş değerler alınmıştır. Bulanık AHP yöntemiyle bu kriterlere ait önem dereceleri (ağırlıklar) bir lojistik uzmanından alınan görüşler doğrultusunda hesaplanmıştır. GİA yöntemiyle ise bu 10 ülkeye ait lojistik performans hesaplanmış ve sıralama gerçekleş̧irilmiştir.

1. Aşama: Kriterlerin Belirlenmesi ve Verilerin Elde Edilmesi

Dünya Bankası 2007 yılından bu yana, altı göstergeye göre ülkelere Lojistik Performans İndeksi (LPI) hesaplamaktadır. $\mathrm{Bu}$ göstergeler; ülkelere ait gümrük ve sınırların etkinliği, ticaret ve ulaşımla altyapılarının kalitesi, uluslararası gönderilerin fiyatlarının düzenlenmesi konusundaki esneklik, lojistik hizmetlerin yeterliliği ve kalitesi, gönderileri takip etme yeteneği, gönderilerin planlanan veya beklenen teslim süresi içinde alıcılara ulaşma sıklı̆̆ şeklinde sayılabilir (Dünya Bankası, LPI Raporu, 2018).

Dünya Bankası, anket yoluyla çeșitli ülkelerde uluslararası alanda faaliyet gösteren lojistik işletmelerinde çalışan yaklaşık 1000 profesyonelden elde ettiği verilerle bu 6 temel gösterge çerçevesinde bir hesaplama gerçekleştirmektedir. Ankette yer alan ölçekler 1'den (en düşük) 5'e (en yüksek) kadar olup, temel Bileșenler Analizi (TBA) tekniği kullanılarak bu göstergeler şu şekilde ağırlıklandırılmıştır; gümrük 0,42 , altyapı 0,42 , uluslararası sevkiyat 0,37 , lojistik yetkinlik 0,42 , takip ve izlenebilirlik 0,41, zamanlama 0, 40 (Bayraktutan ve Özbilgin, 2015).

Dünya bankasının indeksi dışında global anlamda periyodik olarak yayınlanan ve lojistik performansı ölçen diğer indeksler mevcuttur, bunlar; Baltık Kuru İndeksi, Agility İndeks ve Küresel Lojistik Rehberi (Inbound dergisi tarafından), Düzenli Hat Taşımacıllı̆̆ Bağlanabilirlik İndeksi'dir.

Çalışmada gerçeği en iyi şekilde temsil edeceği düşünülen kriterlerden 5 tanesi kullanılarak ülkelerin LPI hesaplanmıștır. Bu kriterler; ihracat teslim süresi, ithalat teslim süresi, Ticaret ve ulaşım ile ilgili altyapının kalitesi, gönderilerin planlanan veya beklenen süre içerisinde alıcıya ulaşma sıklığı, gönderileri takip etme yeteneği şeklindedir. "ihracat teslim süresi ve ithalat teslim süresi" kriterlerine ait verilerin birim "gün" şeklindedir diğer kriterlere ait veriler ise anket sonuçlarından elde edilen 1'den 5' e kadar puanlama şeklindedir. Tüm bu veriler Dünya Bankası LPI 2016 ölçümlerinden elde edilmiştir. Çalışmanın ele alındığı 2018 yılında, ülkelerin bu çalışmada ele alınan kriterlere dair, Dünya Bankası'nda en son yayınlanan puanlama verilerinin 2016 yılına ait olduğu görülmektedir (Dünya Bankası, 2018). 
Ele alınan lojistik performans kriterlerini açıklamak gerekirse;

İhracat Teslim Süresi (K1): İhraç olacak ürünlere ait siparişin verilmesi ile sipariş edilen malların alınması arasında geçen süreyi temsil etmektedir. İhracat tedariği usulleri ithalat usullerinden daha hafif unsurlar içerdiğinden teslim süreleri ithalattan daha kısa olmaktadır. Bu sürenin minimum olması hedeflenmektedir. İhracat teslim süresi performansı yapılacak olan sevkiyatın hava, deniz veya karayoluyla olmasına göre değişim göstermektedir.

Şekil 1. Lojistik Performans Değerlendirmesi Uygulama Aşamaları

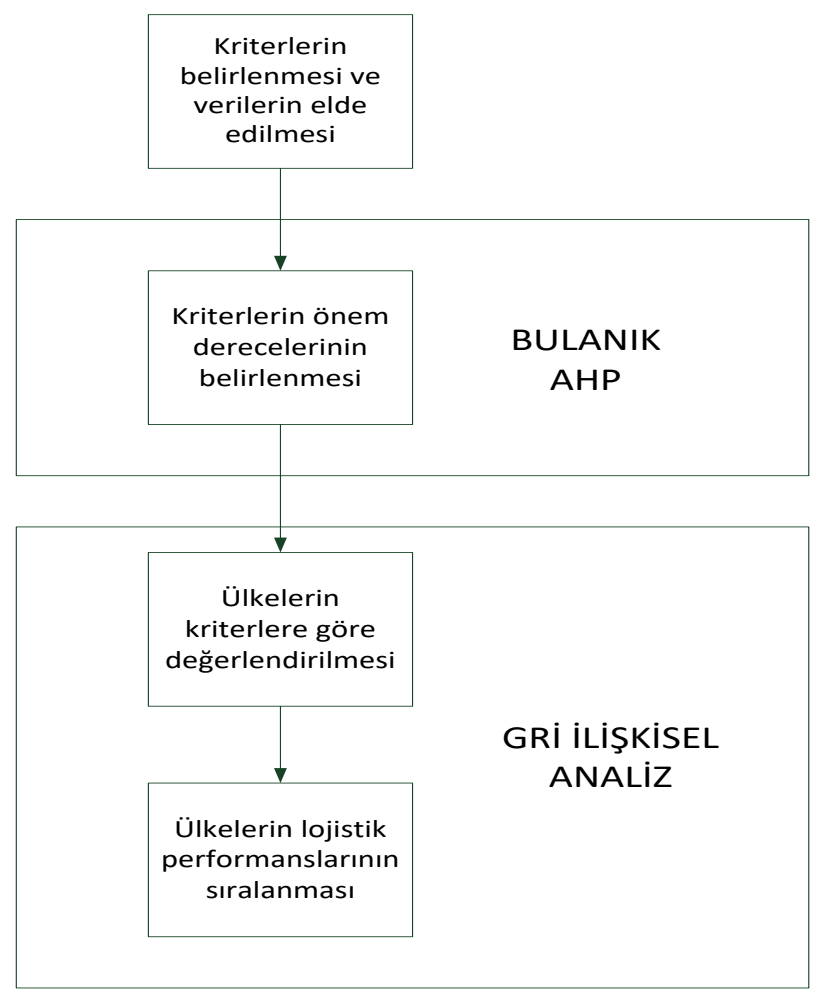

İthalat Teslim Süresi (K2): İthal edilecek ürünlere ait siparișin verilmesi ile sipariș edilen malların teslim alınması arasında geçen süreyi temsil etmektedir $\mathrm{Bu}$ sürenin de minimum olması hedeflenmekte ve rapora göre en iyi performans gösteren ülkelerde bu süre ortalama 3 gün civarındadır. En düşük performans gösteren ülkelerde ise bu süre ortalama 10- 12 gün arasında değişmektedir. İthalat teslim süresi performansı yapılacak olan sevkiyatın hava, deniz veya karayoluyla olmasına göre değişim göstermektedir.
Ticaret ve Ulaşım İle İlgili Altyapının Kalitesi (K3): Bu kriter teslim sürelerine de etki etmektedir. Ülkelerin sahip olduğu ekonomik imkanlarla orantılı olarak ticari ve ulaşım altyapılarının da kalitesi değişmektedir. Burada altyapıdan kasıt sahip olunan bilişim teknolojileri, demiryolları, hava yolu imkanları ve karayollarının durumudur.

Gönderilerin Planlanan veya Beklenen Süre İçerisinde Alıcıya Ulaşma Sıklığg (K4): Bu performans kriteri de diğer kriterlerin performansıyla ilişkilidir. Sevk edilen ürünlerin müşteriye planlanan zamanda ulaşması neticesinde güvenilirlik ve müşterinin memnuniyeti artmakta, pazarda rekabet gücü yükselmektedir.

Gönderileri Takip Etme Yeteneği (K5): Sevk edilen ürünlerin takip edilebilir ve güncel olarak izlenebilir olması lojistik performansına etki eden önemli bir kriterdir. Kullanılan teknolojik aygitlarla gönderinin geçmişte ve gelecekte hangi lokasyonda olduğunu ne tür lojistik aşamalardan geçtiğini takip etmek mümkündür. Gönderileri takip etme yeteneği performansı hem kullanılan bilişim teknolojileri hem de istihdam edilen personelin kalitesiyle ilişkilidir.

2. Aşama: Kriterlerin Önem Derecelerinin (Ağırlıklarının) Elde Edilmesi

Kriterlerin ağırlıklarının belirlenmesi için Bulanık AHP Yöntemi kullanılmıștır. Bunun için bir lojistik uzmanının bir önceki aşamada belirlenen kriterlerin göreli önemlerini dilsel olarak tanımlaması istenmiştir. $\mathrm{Bu}$ dilsel ifadeler öncelikle bulanık dilsel ifadelere dönüştürülmüştür. Tablo 2'de kriterlerin bulanık ikili karşılaştırma matrisi yer almaktadır

Daha sonra bu bulanık karşılaştırma matrisi eşitlik (1- 6) aracılığıyla genişletme işlemine tabi tutulmuş ve kriterlerin olabilirlik dereceleri belirlenmiştir. Tablo 3'de her bir kriterin olabilirlik derecesi görülmektedir.

Eşitlik (7-10) aracılığıyla Tablo 4'te verilmiş olan kriterlere ait ağırlıklar belirlenmiştir.

Tablo 2. Kriterlerin Bulanık İkili Karşılaștırma Matrisi

\begin{tabular}{|c|c|c|c|c|c|c|c|c|c|c|c|c|c|c|c|c|c|}
\hline \multirow{2}{*}{$\begin{array}{c}\text { KRİTERLER } \\
\text { K1 }\end{array}$} & \multicolumn{4}{|c|}{ K1 } & \multicolumn{4}{|c|}{$\mathbf{K} 2$} & \multicolumn{4}{|c|}{ K3 } & \multicolumn{2}{|r|}{ K4 } & \multicolumn{3}{|c|}{ K5 } \\
\hline & & & $\begin{array}{lll}1 & 1 & 1\end{array}$ & & & 1 & 3 & 5 & & & 3 & 5 & 13 & 5 & & 5 & 7 \\
\hline $\mathrm{K} 2$ & & 0. & 20.333 & 1 & & & 1 & 1 & & & 3 & 5 & 35 & 7 & 3 & 5 & 7 \\
\hline K3 & & 0 . & 20.333 & 1 & 0.2 & 0.333 & 1 & & & & 1 & 1 & 35 & 7 & 1 & 3 & 5 \\
\hline K4 & & & $2 \quad 0.333$ & 1 & & 0.142 & 0.2 & 0.333 & & 0.142 & 0.2 & 0.333 & 11 & 1 & 1 & 3 & 5 \\
\hline K5 & 0.142 & 0.2 & 0.333 & & & 0.142 & 0.2 & 0.333 & 0.2 & 0.333 & 1 & & 0.2 & $\begin{array}{lll}2 & 0.333 & 1\end{array}$ & 1 & 1 & 1 \\
\hline
\end{tabular}


Tablo 3. Kriterlerin Olabilirlik Dereceleri

\begin{tabular}{lc}
\hline İhracat Teslim Süresi (K1) & 1 \\
İthalat Teslim Süresi (K2) & 0.981 \\
Ticaret ve Ulaşım İle İlgili Altyapının Kalitesi (K3): & 0.813 \\
Gönderilerin Planlanan Veya Beklenen Süre İçerisinde Alıcıya Ulaşma Sıklığı (K4): & 0.479 \\
Gönderileri Takip Etme Yeteneği (K5): & 0.105 \\
\hline
\end{tabular}

3. Aşama: Ülkelerin Lojistik Performanslarının Gri İlişkisel Analiz ile Değerlendirilmesi

Gri ilişkisel analiz yöntemiyle ülkelere ait lojistik performans değerlendirilmesi yapılmıştır. Burada kullanılan ağırlıklar bir önceki aşamada Bulanık AHP yöntemiyle elde edilmiştir.

Kriterlerden K1 ve K2 minimize edilmek istenen K3, K4 ve $\mathrm{K} 5$ ise maksimize edilmek istenen değerlerden oluşmaktadır. Her bir kritere karşılık gelen Dünya Bankasından elde edilen veriler Tablo 5'de görülmektedir. Ayrica bu tabloda bir de Referans satırı bulunmakta, bu satır K1 Ve K2'nin en küçük diğer kriterlerin ise en büyük olduğu değere tekabül etmektedir. Eşitlik 14 ve 15 aracılığıyla Tablo 6'da bulunan normalize edilmiş karar matrisi oluşturulmuştur. Eşitlik 18 aracılığıyla Tablo 7'de bulunan mutlak değer tablosu oluşturulmuştur. Eşitlik 20 aracılığıyla ülkelerin kriterlere göre gri ilişkisel katsayıları hesaplanmış ve Tablo 8'de sunulmuştur. Burada $\zeta$ literatüre uygun olarak 0,5 alınmıştır.

\section{Aşama: Ülkelerin Lojistik Performans Sıralamasının} Gerçekleştirilmesi

Eşitlik 22 ve Bulanık AHP yöntemiyle elde edilen kriter ağırlıkları da kullanılarak ülkelerin ağırlıklı gri ilişskisel dereceleri ve lojistik performans sıralamaları elde edilmiştir ve Tablo 9'da gösterilmiştir.

Tablo 4. Kriterlerin Önem Dereceleri (Ağırlıkları)

\begin{tabular}{lc}
\hline İhracat Teslim Süresi (K1) & 0.296 \\
İthalat Teslim Süresi (K2) & 0.29 \\
Ticaret ve Ulaşım İle İlgili Altyapının Kalitesi (K3): & 0.241 \\
Gönderilerin Planlanan Veya Beklenen Süre İçerisinde Alıcıya Ulaşma Sıklığ1 (K4): & 0.142 \\
Gönderileri Takip Etme Yeteneği (K5): & 0.031 \\
\hline
\end{tabular}

Tablo 5. Karar Matrisi

\begin{tabular}{llllll}
\hline Ülkeler & K1 & K2 & K3 & K4 & K5 \\
\hline REFERANS & 1 & 2 & 4.44 & 4.45 & 4.36 \\
Türkiye & 2 & 2 & 3.49 & 3.75 & 3.39 \\
Almanya & 3 & 3 & 4.44 & 4.45 & 4.27 \\
Birleşik Krallık & 2 & 3 & 4.21 & 4.33 & 4.13 \\
İtalya & 2 & 3 & 3.79 & 4.03 & 3.86 \\
Yunanistan & 3 & 3 & 3.32 & 3.85 & 3.59 \\
Belçika & 2 & 3 & 4.05 & 4.43 & 4.22 \\
İspanya & 3 & 4 & 3.72 & 4 & 3.82 \\
Avusturya & 2 & 2 & 4.08 & 4.37 & 4.36 \\
Çek Cumhuriyeti & 5 & 5 & 3.36 & 3.94 & 3.84 \\
Avustralya & 1 & 2 & 3.82 & 4.04 & 3.87 \\
\hline
\end{tabular}


Tablo 6. Normalize Edilmiș Karar Matrisi

\begin{tabular}{|c|c|c|c|c|c|}
\hline Ülkeler & K1 & K2 & K3 & K4 & K5 \\
\hline REFERANS & 1.000 & 1.000 & 1.000 & 1.000 & 1.000 \\
\hline Türkiye & 0.750 & 1.000 & 0.152 & 0.000 & 0.000 \\
\hline Almanya & 0.500 & 0.667 & 1.000 & 1.000 & 0.907 \\
\hline Birleşik Krallık & 0.750 & 0.667 & 0.795 & 0.829 & 0.763 \\
\hline İtalya & 0.750 & 0.667 & 0.420 & 0.400 & 0.485 \\
\hline Yunanistan & 0.500 & 0.667 & 0.000 & 0.143 & 0.206 \\
\hline Belçika & 0.750 & 0.667 & 0.652 & 0.971 & 0.856 \\
\hline İspanya & 0.500 & 0.333 & 0.357 & 0.357 & 0.443 \\
\hline Avusturya & 0.750 & 1.000 & 0.679 & 0.886 & 1.000 \\
\hline Çek Cumhuriyeti & 0.000 & 0.000 & 0.036 & 0.271 & 0.464 \\
\hline Avustralya & 1.000 & 1.000 & 0.446 & 0.414 & 0.495 \\
\hline
\end{tabular}

Tablo 7. Mutlak Değer Tablosu

\begin{tabular}{llllll}
\hline Ülkeler & K1 & K2 & K3 & K4 & K5 \\
\hline Türkiye & 0.250 & 0.000 & 0.848 & 1.000 & 1.000 \\
Almanya & 0.500 & 0.333 & 0.000 & 0.000 & 0.093 \\
Birleşik Krallık & 0.250 & 0.333 & 0.205 & 0.171 & 0.237 \\
İtalya & 0.250 & 0.333 & 0.580 & 0.600 & 0.515 \\
Yunanistan & 0.500 & 0.333 & 1.000 & 0.857 & 0.794 \\
Belçika & 0.250 & 0.333 & 0.348 & 0.029 & 0.144 \\
İspanya & 0.500 & 0.667 & 0.643 & 0.643 & 0.557 \\
Avusturya & 0.250 & 0.000 & 0.321 & 0.114 & 0.000 \\
Çek Cumhuriyeti & 1.000 & 1.000 & 0.964 & 0.729 & 0.536 \\
Avustralya & 0.000 & 0.000 & 0.554 & 0.586 & 0.505 \\
\hline
\end{tabular}

Tablo 8. Gri İlişkisel Katsayılar

\begin{tabular}{|c|c|c|c|c|c|}
\hline Ülkeler & K1 & K2 & K3 & K4 & K5 \\
\hline Türkiye & 0.666 & 1 & 0.371 & 0.333 & 0.333 \\
\hline Almanya & 0.5 & 0.6 & 1 & 1 & 0.843 \\
\hline Birleşik Krallık & 0.666 & 0.6 & 0.709 & 0.744 & 0.678 \\
\hline İtalya & 0.666 & 0.6 & 0.463 & 0.454 & 0.492 \\
\hline Yunanistan & 0.5 & 0.6 & 0.333 & 0.368 & 0.386 \\
\hline Belçika & 0.666 & 0.6 & 0.589 & 0.946 & 0.776 \\
\hline İspanya & 0.5 & 0.429 & 0.4375 & 0.4375 & 0.473 \\
\hline Avusturya & 0.666 & 1 & 0.609 & 0.814 & 1 \\
\hline Çek Cumhuriyeti & 0.333 & 0.333 & 0.341 & 0.407 & 0.482 \\
\hline Avustralya & 1 & 1 & 0.474 & 0.46 & 0.497 \\
\hline \multicolumn{6}{|c|}{ DELTA MAKS 1} \\
\hline \multicolumn{6}{|c|}{ DELTA MIN 0} \\
\hline$\zeta$ & 0.5 & & & & \\
\hline
\end{tabular}


Tablo 9. Ağırlıklı Gri İlişkisel Dereceler ve Sıralama

\begin{tabular}{lccccccc}
$\begin{array}{l}\text { Kriter } \\
\text { Ă̆ırlıkları }\end{array}$ & $\mathbf{0 . 2 9 6}$ & $\mathbf{0 . 2 9}$ & $\mathbf{0 . 2 4}$ & $\mathbf{0 . 1 4 1}$ & $\mathbf{0 . 0 3 1}$ & \multirow{2}{*}{$\boldsymbol{\Gamma}$ SIRALAMA } \\
\cline { 1 - 5 } Ülkeler & $\mathbf{K 1}$ & $\mathbf{K 2}$ & $\mathbf{K 3}$ & $\mathbf{K 4}$ & $\mathbf{K 5}$ & & \\
\hline Türkiye & 0.667 & 1 & 0.371 & 0.333 & 0.333 & 0.634 & 6 \\
Almanya & 0.5 & 0.6 & 1 & 1 & 0.843 & 0.729 & 3 \\
Birleşik Krallık & 0.667 & 0.6 & 0.709 & 0.745 & 0.678 & 0.667 & 5 \\
İtalya & 0.667 & 0.6 & 0.463 & 0.455 & 0.492 & 0.562 & 7 \\
Yunanistan & 0.5 & 0.6 & 0.333 & 0.368 & 0.386 & 0.466 & 8 \\
Belçika & 0.667 & 0.6 & 0.589 & 0.946 & 0.776 & 0.67 & 4 \\
İspanya & 0.5 & 0.429 & 0.438 & 0.438 & 0.473 & 0.454 & 9 \\
Avusturya & 0.667 & 1 & 0.609 & 0.814 & 1 & 0.779 & 2 \\
Çek & 0.333 & 0.333 & 0.341 & 0.407 & 0.483 & 0.35 & 10 \\
Cumhuriyeti & 1 & 1 & 0.475 & 0.461 & 0.497 & 0.78 & 1 \\
Avustralya & & & & &
\end{tabular}

\section{Sonuç}

$\mathrm{Bu}$ çalışmada bütünleşik olarak bulanık AHP ve GİA yöntemleri kullanılarak OECD üyesi 10 ülke için lojistik performans değerlendirmesi gerçekleştirilmiştir. Literatürde Lojistik performans değerlendirmesi ile ilgili birçok çalışma mevcut olsa da, değerlendirme için bütünleşik olarak bulanık AHP ve GİA metotlarını kullanan başka bir çalışma bulunmamaktadır. Çalışma bu yönüyle literatüre yeni bir katkı sağlamaktadır. Çalışmanın ayrı bir katkısı ise, ele alınan örnek vakada OECD üyesi 10 ülkenin lojistik performansları gerçek veriler ile değerlendirmesidir. Bu örnek vaka ile çalışma, uluslararası nitelikte bir performans değerlendirme örneği sunmuş olsa da; araştırmacılara farklı sektörlerde lojistik performans değerlendirmesi için farklı farklı kriterler ile kullanılabilir esnek bir metot önermektedir.

Ele alınan değerlendirme kriterleri ve bunların bulanık AHP yöntemiyle elde edilmiş ağırlıkları şu şekildedir: ihracat teslim süresi $(0,296)$, ithalat teslim süresi $(0,290)$, ticaret ve ulaşım ile ilgili altyapının kalitesi $(0,241)$, gönderilerin planlanan veya beklenen süre içerisinde alıcıya ulaşma sıklığı $(0,142)$, gönderileri takip etme yeteneği (0,031).

Ülkelerin lojistik performans sıralaması şu şekildedir; en yüksek performansa sahip olan ülke Avustralya olup onu sırasıyla Avusturya, Almanya, Belçika, Birleşik Krallık, Türkiye, İtalya, Yunanistan, İspanya ve Çek Cumhuriyeti takip etmektedir. Ülkelerin lojistik performanslarının öncelikle ithalat ve ihracat teslim sürelerine daha sonra ise kullandıkları altyapıların kalitesine bağlı olduğu sonucuna erişilmiştir.

\section{Kaynakça}

Andersson, P., Aronsson, H. ve Storhagen, N. G. (1989). Measuring Logistics Performance. Engineering Costs and Production Economics, 17(1-4), 253-262.
Ahi, P. \& Searcy, C. (2015). An Analysis of Metrics Used to Measure Performance in Green and Sustainable Supply Chains. Journal of Cleaner Production, 86,360-377.

Avelar-Sosa, L., García-Alcaraz, J. L., Vergara-Villegas, O. O., Maldonado-Macías, A. A. ve Alor-Hernández, G. (2015). Impact of Traditional and international logistic policies in supply chain performance. Int $\mathrm{J} A d v$ Manuf Technol, 76:913-925.

Bayraktutan, Y., Özbilgin, M. (2015). Lojistik Maliyetler ve Lojistik Performans Ölçütleri. Maliye Araştırmaları Dergisi, 1-2, 95-112.

Cagliano, A.C.\& Rafele, C. (2006). Using System Dynamics to Evaluate Logistic Performance. International Meetings for Research in Logistics, 445457.

Caplice, C.\& Sheffi, Y. (1995). A Review and Evaluation of Logistics Performance Measurement Systems. The International Journal of Logistics Management,6,1, 61-74.

Chan, F. T. S., Chan, H.K., Lau, H. C. W., ve Ip, R. W. L. (2006). An AHP Approach in Benchmarking Logistics Performance of the Postal Industry, Benchmarking: An International Journal, 13 (6), 636-661.

Chang, D. Y. (1996). Applications of the Extent Analysis Method on Fuzzy AHP. Eur J Oper Res, 95, 649-655.

Deng Julong (1982). Control Problems of Grey Systems, Systems and Control Letters, 5, 288-294.

Dünya Bankası. 2016. Lojistik Performans İndeksi. Erişim ( 30.08.2018) https://data.worldbank.org/indicator/LP.LPI.OVRL.X $\mathrm{Q}$ ?view=chart

Erkan, B. (2014). The Importance and Determinants of Logistics Performance of Selected Countries, Journal of Emerging Issues in Economics, Finance and Banking, 3(6), 1237-1254. 
Fawcett, S. E. \& Cooper, M. B. (1998). Logistics Performance Measurement and Customer Success. Industrial Marketing Management, 27(4), 341-357.

Fugate, B. S., Autry, C. W., Davis-Sramek, B. ve Germain, R. N. (2012). Does Knowledge Management Facilitate Logistics-Based Differentiation? The Effect of Global Manufacturing Reach. International Journal of Production Economics, 139(2), 496-509.

Hanaoka, S. \& Kunadhamraks, P. (2009). Multiple Criteria and Fuzzy Based Evaluation of Logistics Performance for Intermodal Transportation. Journal of Advanced Transportation, 43(2), 123-153.

Hsiao, H., Kemp, R. G. M., Van der Vorst, J. G. A. J. ve Omta, S. O. (2010). A Classification of Logistic Outsourcing Levels and Their Impact on Service Performance: Evidence 117 from the Food Processing Industry. International Journal of Production Economics, 124(1), 75-86.

Jothimani, D. \& Sarmah, S. P. (2014). Supply Chain Performance Measurement for Third Party Logistics, Benchmarking: An International Journal, 21(6), 944963.

J. J. Buckley. (1985). Ranking Alternatives Using Fuzzy Numbers, Fuzzy Sets Systems,15(1), 21-31.

Kazancoglu, Y., Kazancoglu, I. ve Sagnak, M. (2018) Fuzzy DEMATEL-Based Green Supply Chain Management Performance: Application in Cement Industry. Industrial Management \& Data Systems, 118(2), 412-431.

Korpela, J. \& Tuominen, M. (1996). Benchmarking Logistics Performance with an Application of the Analytic Hierarchy Process. Engineering Management, IEEE Transactions, 43(3), 323-333.

Lai, K. H., Bao, Y. \& Li, X. (2008). Channel Relationship and Business Uncertainty: Evidence from the Hong Kong Market. Industrial Marketing Management, 37(6), 713-724.

Lin, P. C. \& Cheng, T. C. E. (2018) The Diffusion and the International Context of Logistics Performance. International Journal of Logistics Research and Applications, DOI:10.1080/13675567.2018.1510907.
Liu, C. L. \& Lyons, A. C. (2011). An Analysis of ThirdParty Logistics Performance and Service Provision. Transportation Research Part E: Logistics and Transportation Review, 47(4), 547-570.

Özceylan, E., Çetinkaya, C., Erbas, M. ve Kabak, M. (2016). Logistic Performance Evaluation of Provinces in Turkey: A GIS-Based Multi-Criteria Decision Analysis. Transportation Research Part A, 94, 323 337.

Piriyakul, M. (2011). A Partial Least Squares Model for SCM Strategy, Willingness for External Collaboration, Competitive Performance and Relative Performance: Effects of Marketing and Logistics Performance in the Palm Oil Industry. African Journal of Business Management, 5(4), 1431-1440.

Puertas, R., Martı', L. ve Garcia, L. (2014). Logistics Performance and Export Competitiveness: European Experience. Empirica, 41, 467-480.

Ramanaa, D.V., Raob, K.N. ve Kumara, J. S. (2013). Evaluation of Performance Metrics of Leagile Supply Chain Through Fuzzy MCDM. Decision Science Letters, 2,211-222.

Ramanathan, R. (2010). The Moderating Roles of Risk and Efficiency on the Relationship between Logistics Performance and Customer Loyalty in e-commerce. Transportation Research Part E: Logistics and Transportation Review, 46(6), 950-962.

T.C. Gümrük ve Ticaret Bakanlığı. (2017). Lojistik Performans İndeksi 2016 Ekonomik Analiz ve Değerlendirme Dairesi, Ankara.

Van-Laarhoven, P. J. M. ve Pedrycz, W. (1983). A Fuzzy Extension of Saaty's Priority Theory. Fuzzy Sets and Systems, 11, 229-241.

Wang, M., Jie, F. ve Abareshi, A. (2015). Business Logistics Performance Measurement in Third-Party Logistics: An Empirical Analysis of Australian Courier Firms. International Journal of Business and Information, 10(3), 323-336.

Wu, H. H. (2002). A Comparative Study of Using Grey Relational Analysis in Multiple Attribute Decision Making Problems. Quality Engineering, 15(2), 209217. 